\title{
Changing appearance of lipomatous hypertrophy of the interatrial septum on positron emission tomography scan
}

\author{
Natalia Siminiak', Justyna Rajewska-Tabor², Małgorzata Pyda², Rafał Czepczyński1, 3, Marek Ruchała' \\ 'Department of Endocrinology, Metabolism and Internal Diseases, Poznan University of Medical Sciences, Poznań, Poland \\ ${ }_{21}^{15 t}$ Department of Cardiology, Poznan University of Medical Sciences, Poznań, Poland \\ ${ }^{3}$ Department of Nuclear Medicine, Affidea Poznan, Poznań, Poland
}

Correspondence to: Natalia Siminiak, MD, Department of

Endocrinology and

Metabolism,

Poznan University of Medical Sciences,

Przybyszewskiego 49, 60-356 Poznań, Poland, phone: +48616 698222 e-mail:

nsiminiak@gmail.com

Copyright by the Author(s), 2021

Kardiol Pol. 2021;

79 (9): 1032-1033:

DOI: 10.33963/KP.a2021.0046

Received:

May 14, 2021

Revision accepted:

June 20, 2021

Published online:

June 22, 2021
We present a rare imaging case of the lipomatous hypertrophy of the interatrial septum (LHIS), which may be correlated with arrhythmia and sudden death. We discuss the possible presence of brown adipose tissue within LHIS.

A 70-year-old female, with pancreatic cancer, underwent a positron emission tomography (PET/CT) examination during follow-up to evaluate the presence of metastases. Two months before the scan, the patient was treated with a pancreatoduodenectomy, which was complicated by an abscess. The PET/CT showed some post-operative inflammatory lesions in the area of surgery and no metastases were found. However, some unusual increased cardiac ${ }^{18} \mathrm{~F}$-fluorodeoxyglucose ( $\left.{ }^{18} \mathrm{~F}-\mathrm{FDG}\right)$ uptake was noted (Figure 1). The focus was located in the area of the interventricular septum. The area had a density of adipose tissue and the following dimensions: $27 \times 14 \times 36 \mathrm{~mm}$. The ${ }^{18} \mathrm{~F}$-FDG uptake was relatively high (maximum standard unit value $=5.7$ ).

Until now, the patient did not suffer from any cardiovascular disease, the echocardiogram did not reveal any pathologies of the heart. Due to the unusual finding, the patient was referred to a cardiologist. The patient underwent the 24-hour monitoring of the electrocardiogram,

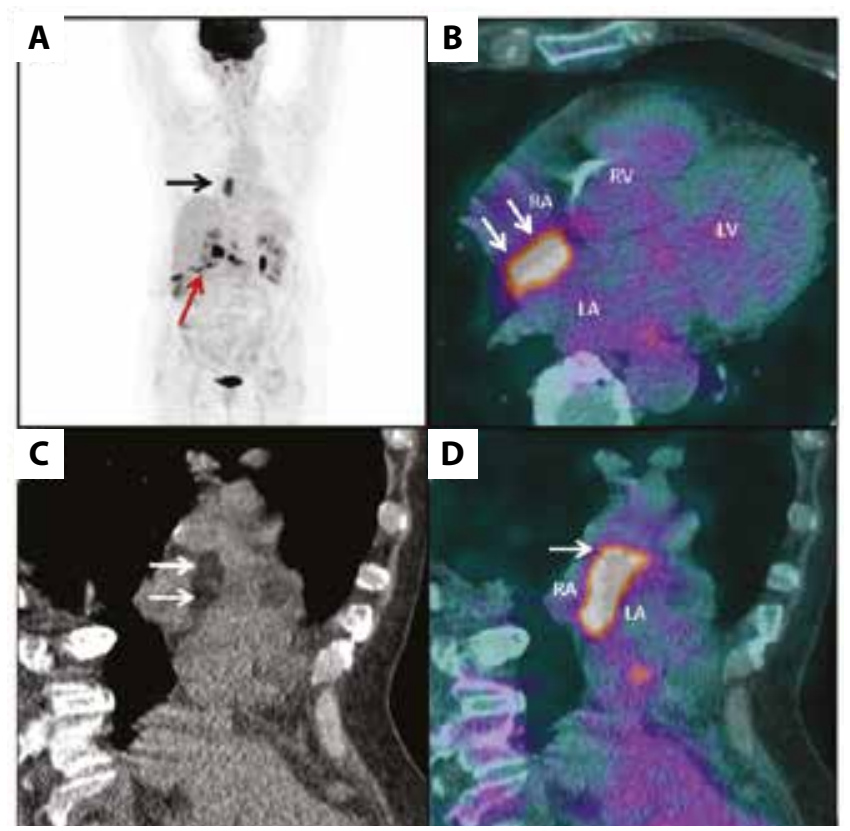

Figure 1. The positron emission tomography (PET/CT) images with increased activity of ${ }^{18} \mathrm{~F}$-fluorodeoxyglucose $\left({ }^{18} \mathrm{~F}-\mathrm{FDG}\right)$ in the interatrial septum. The whole-body PET. A. Post-operative lesions in the abdomen (red arrow) and unusual cardiac activity (black arrow). B. and D. In the PET/CT fused images (B, transaxial image; $D$, sagittal image) the focal cardiac uptake (white arrows) corresponds to the area of fat density in the interatrial septum. C. Sagittal $\mathrm{CT}$ image, white arrows

Abbreviations: LA, left atrium; LV, left ventricle; RA, right atrium; RV, right ventricle 
which did not show any significant arrhythmia. In order to exclude an intracardiac malignancy, the patient was referred to cardiac magnetic resonance (CMR), since it can characterize the cardiac tissue and indicate malignancies [1]. The CMR examination consisted of: the cine imagines, T1-, T2-, T2*-weighted images with or without fat suppression, T1-mapping, and late gadolinium enhancement (LGE) 10-15 minutes after intravenous gadolinium contrast injection [2,3]. The CMR images showed hyperintense signal on T1-weighted sequences before and after contrast injection and on LGE. Native T1-maps of the mass was 174 ms which confirmed the lipomatous tissue.

Based on the CMR, the LHIS was diagnosed. Further management of the pancreatic cancer in this patient included chemotherapy. A follow-up PET/CT scan performed seven months later confirmed complete cancer remission. Interestingly, there was no increased ${ }^{18} \mathrm{~F}$-FDG uptake in the interventricular area on the follow-up scan.

The lipomatous hypertrophy of the interatrial septum is usually a benign disease and appears as diffused thickening of the septum extending from fossa ovalis to the posterior wall of the right atrium and between great vessels [1]. It is rarely diagnosed, usually unintentionally, on echocardiography, CMR, or autopsy. Adipose tissue is physiologically present around the heart, however, in LHIS, there is a relevant idiopathic increase of the adipose tissue mass. LHIS may stay asymptomatic or cause a supraventricular arrhythmia or even sudden cardiac death [4]. Fortunately, our patient was free from life-threatening arrhythmia throughout the observation period. Further observation is still needed.

The conflicting results of two PET/CT scans in an individual patient are relatively common and the mechanism of ${ }^{18} \mathrm{~F}-\mathrm{FDG}$ uptake in LHIS is controversial $[2,5]$. It may indicate the presence of metabolically active brown adipose tissue (BAT) within the LHIS. BAT presents different metabolic activities depending on body temperature. BAT is activated by exposure to cold and is associated with thermogenesis. Some studies demonstrated the different ${ }^{18} \mathrm{~F}-\mathrm{FDG}$ uptake, caused by BAT metabolic activity in some adults [5].

\section{Article information}

Conflict of interest: None declared.

Open access: This article is available in open access under Creative Common Attribution-Non-Commercial-No Derivatives 4.0 International (CC BY-NC-ND 4.0) license, allowing to download articles and share them with others as long as they credit the authors and the publisher, but without permission to change them in any way or use them commercially. For commercial use, please contact the journal office at kardiologiapolska@ptkardio.pl.

How to cite: Siminiak N, Rajewska-Tabor J, Pyda M, et al. Changing appearance of lipomatous hypertrophy of the interatrial septum in the positron emission tomography scan. Kardiol Pol. $2021 ; 79(9)$ : 1032-1033, doi: 10.33963/KP.a2021.0046.

\section{REFERENCES}

1. Fussen S, De Boeck BWL, Zellweger MJ, et al. Cardiovascular magnetic resonance imaging for diagnosis and clinical management of suspected cardiac masses and tumours. Eur Heart J. 2011; 32(12): 1551-1560, doi: 10.1093/eurheartj/ehr104, indexed in Pubmed: 21498848.

2. Baffour FI, Wenger DE, Broski SM. F-FDG PET/CT imaging features of lipomatous tumors. Am J Nucl Med Mol Imaging. 2020; 10(1): 74-82, indexed in Pubmed: 32211221.

3. Stojanovska J, Attili AK. AJR teaching file: fat-containing mass in the interatrial septum. AJR Am J Roentgenol. 2010; 195(Suppl 6): S73-S75, doi: 10.2214/AJR.09.7173, indexed in Pubmed: 21098164.

4. Fatma A, El-Sabbagh A, Muzaffar R, Osman M. Lipomatous hypertrophy of the inter-atrial septum: FDG PET/CT appearance and clinical correlation. J Nucl Med. 2017; 58 (Suppl. 1): 964.

5. Frontini A, Cinti S. Distribution and development of brown adipocytes in the murine and human adipose organ. Cell Metab. 2010; 11(4): 253-256, doi: 10.1016/j.cmet.2010.03.004, indexed in Pubmed: 20374956. 